Agora Rev Cient. 2014; 01(1): 5-6

\title{
Procesos Editoriales de una Revista Científica
}

El conocimiento es, sin duda, uno de los más eficaces instrumentos de transformación y progreso, las nuevas tendencias cada vez más globalizadas exigen del ser humano el desarrollo de una serie de capacidades, para comprender y explicar la realidad en la que les toca vivir. Estas capacidades están relacionadas fundamentalmente a la tarea investigativa que deben desarrollar con la finalidad de conocer, comprender y transformar la realidad en la que interactúan.

En este contexto, una Revista Científica es una publicación periódica en la que se intenta recoger el progreso de la ciencia, normalmente informando de los resultados de las nuevas investigaciones. Garantiza la originalidad, calidad y autoría de sus contenidos. Muchas revistas científicas son altamente especializadas, aunque algunas de las más antiguas (como Nature y Science) publican artículos en un amplio rango de campos científicos. Este proceso se inicia desde que un investigador o institución concibe la idea de crear una Revista, hasta la indización de la misma en una base de datos internacional, siendo el responsable del proceso el Comité Editorial

En el marco de los diversos procesos editoriales, el Editor de una revista científica, está en posición de tomar decisiones, por tanto debe poseer experiencia, experticia y conocimientos en el área al que está dedicada la revista. Debemos de manifestar que a la gran mayoría de los directores de revistas se les escoge por haber hecho aportes importantes a sus disciplinas, más que por sus conocimientos en materia de publicación. Sin embargo, factores como tener conocimientos de metodología científica y estadística, haber publicado anteriormente y haber formado parte de una junta editorial, así como el tener competencias críticas y analíticas, pueden ser factores para que un científico sea un mejor director de revista que otro de igual formación pero sin ninguna experiencia editorial.

Los Editores de revistas deben seleccionar trabajos que sean novedosos y originales y que aporten conocimientos relevantes; que presenten resultados válidos y repetibles en suficiente detalle para que los lectores puedan valorar la validez de las inferencias; que tengan lógica y coherencia y hagan debida mención de trabajos anteriores. Los editores sean o no expertos en la temática de la revista, deben apoyarse en los conocimientos de otros editores, asesores y árbitros, asimismo se apoya en árbitros, que son expertos en los temas tratados en los trabajos, para que le proporcionen evaluaciones críticas de la precisión, fiabilidad y validez de estos. Los Editores también dependen de asistentes editoriales y correctores de estilo para mejorar los aspectos sustantivos y técnicos de los trabajos aceptados, asegurándose de que estos tengan corrección gramatical, coherencia estilística y terminológica, precisión y legibilidad.

Los Editores de revistas deben definir claramente y poner en práctica las normas éticas de la revista. Aunque el Editor debe estar atento a posibles violaciones de estas normas, no es su cometido investigar, juzgar o castigar a los autores que cometen infracciones; sin embargo tiene la responsabilidad de informar a los lectores cuando se descubre formalmente que ha habido plagio, invención o falsificación de datos.

Los Editores de revistas deben establecer procedimientos para velar por la calidad de la revista, identificar errores y problemas, detectar tendencias que reflejen un deterioro de la calidad y poner en marcha acciones correctoras según sea necesario. Cualquier error en un artículo publicado debe darse a conocer mediante una nota de corrección o fe de errata; los Editores de revistas tienen la responsabilidad de observar las normas de publicación y los procedimientos establecidos por su organización patrocinadora, así como los términos particulares que puedan especificarse en su contrato con esa entidad. Se entiende que esto abarca el manejo responsable de la revista desde el punto de vista técnico y la adhesión al calendario de publicación establecido. 
Por ultimo a nuestro humilde parecer, es preferible pecar por exceso de divulgación que por defecto. Con la ayuda de los autores, revisores y editores invitados; los editores de revistas debemos saber seleccionar los artículos científicos originales más importantes y de alto impacto, en la resolución de problemas significativos vinculados a las líneas de investigación de la revista.

Dr. Walter Gómez ${ }^{1, a}$

${ }^{1}$ Oficina de Investigación y Creatividad Intelectual - Universidad María Auxiliadora- Lima- Perú

${ }^{a}$ Editor Jefe - AGORA Revista Científica 